\title{
New 2,5-bis(2-ethylhexyl)pyrrolo[3,4-c]pyrrole-1,4(2H,5H)- dione-2,2'-bipyridine-based co-polymer, synthesis, photophysical properties and response to metal cations
}

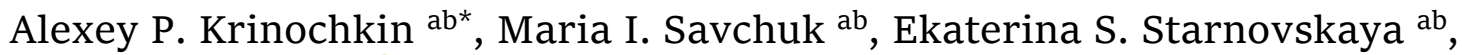
Igor L. Nikonov ${ }^{\text {ab }}$ (D), Artem V. Baklykov ${ }^{\text {ab }}$, Ekaterina A. Kudryashova ${ }^{a}$, Svetlana S. Rybakova ${ }^{a}$, Evgeny D. Ladin ${ }^{a}$, Dmitry S. Kopchuk ${ }^{\text {ab }}$ (D), Zhuo Wang ${ }^{\mathrm{c}}$,Oleg N. Chupakhin ${ }^{\mathrm{ab}}$

a: Ural Federal University, 620002 Mira st., 19, Yekaterinburg, Russia

b: I.Ya. Postovsky Institute of Organic Synthesis of the Ural Branch of the RAS, 620990 Kovalevskoy/Akademicheskaya st., 22/20, Yekaterinburg, Russia

c: Beijing University of Chemical Technology, 100029 Beijing, China

* Corresponding author: yapet89@mail.ru

This short communication (letter) belongs to the regular issue.

(c) 2021, The Authors. This article is published in open access form under the terms and conditions of the Creative Commons Attribution (CC BY) license (http://creativecommons.org/licenses/by/4.o/).

\begin{abstract}
A new co-polymer based on fragments of 2-(2pyridyl)monoazatriphenylene and 2,5-bis (2-ethylhexyl)-3,6di(thiophen-2-yl)pyrrolo[3,4-c]pyrrole-1,4(2H,5H)-dione was prepared by using the Sonogashira reaction. The photophysical properties of the polymer were studied. The presence of a strong bathochromic shift of the absorption and emission maxima in comparison with the previously described monomer units is shown. The polymer exhibits an intense "turn-off" response toward $\mathrm{Cu}^{2+}$ cations.
\end{abstract}

\section{Keywords}

Sonogashira coupling

polymer

monoazatriphenylene

3,6-di(thiophen-2-

yl)pyrrolo[3,4-c]pyrrole-

$1,4(2 H, 5 H)$-dione

fluorescence

$\mathrm{Cu}^{2+}$ "turn-off" response

Received: 16.12 .2021

Revised: 19.12.2021

Accepted: 23.12.2021

Available online: 24.12 .2021

\section{Introduction}

Acetylene-based polymers find a variety of applications as functional materials for sensorics and molecular electronics [1]. In particular, conjugated polymers containing 2,2'-bipyridine moieties [2] as monomer units are of interest in terms of optical response to metal cations [3]. Thus, the selective determination of $\mathrm{Cu}^{2+}$ [4] and $\mathrm{Hg}^{2+}$ [5] cations has been described with the help of such polymers. On the other hand, bis-pyrrolo[3,4-c]pyrrole-1,4(2H,5H)-diones (DPPs) were widely used as components of donor-acceptor alternating co-polymers, which were reported as promising hole-transport materials [6,7], as materials for molecular electronics and photovoltaics [8,9], components of laser dyes [10], dyes for two-photon fluorescence microscopy [11], chemosensors for $\mathrm{Cu}^{2+}$ [12] and $\mathrm{Hg}^{2+}$ [13] cations, and many other applications [14]. One of the most important application of DPP-based materials was in their use as rea- gents for photothermal therapy of cancer [15], including photoacoustic imaging-guided photothermal therapy [16].

In this work, we wish to report the synthesis of a polymer containing fragments of 2-(2-pyridyl)monoazatriphenylene and 2,5-bis(2-ethylhexyl)-3,6-bis(thiophen-2-yl)pyrrolo[3,4c]pyrrole-1,4(2H,5H)-dione.

\section{Experimental}

${ }^{1} \mathrm{H}$ NMR spectra were recorded on a Bruker Avance-40o spectrometer ( $400 \mathrm{MHz}$ ), the internal standard was $\mathrm{SiMe}_{4}$. Elemental analysis was performed on a Perkin Elmer PE 2400 II CHN analyzer. UV-visible absorption spectra were recorded on a Perkin Elmer Lambda 45. Luminescence spectra were obtained using a HORIBA Scientific FluoroMax-4 spectrofluorometer. GPC measurements were performed using a chromatograph Agilent 1200 with an aerosol light scattering detector (ELSD) (Agilent technologies, 
USA). The starting monomers 1 [17] and 2 [18] were obtained as described in the literature.

The chemical polymerization process was carried out in accordance with the modified method [19]. The compounds 1 (33 $\mathrm{mg}$, $0.048 \mathrm{mmol}$ ) and 2 (19.1 $\mathrm{mg}$, $0.048 \mathrm{mmol}$ ) were dissolved in the mixture of diisopropylamine/toluene $(2: 3,4.0 \mathrm{ml})$. Then CuI $(5.8 \mathrm{mg}$, $0.030 \mathrm{mmol}), \mathrm{Pd}(\mathrm{tpp})_{2} \mathrm{Cl}_{2}(3.4 \mathrm{mg}, 0.0048 \mathrm{mmol})$ and $\mathrm{PPh}_{3}$ (2.5 mg, $0.01 \mathrm{mmol}$ ) were added. The reaction mixture was stirred in an autoclave under argon atmosphere at $65{ }^{\circ} \mathrm{C}$ for 3 days. Then the solvents were evaporated under reduced pressure. Water $(10 \mathrm{ml})$ was added to the residue and the product was extracted with methylene chloride $(3 \times 10 \mathrm{ml})$. The organic phase was washed with an aqueous solution of $\mathrm{NH}_{4} \mathrm{Cl}$ and then dried over anhydrous $\mathrm{Na}_{2} \mathrm{SO}_{4}$. The solvent was evaporated under reduced pressure. The polymer was obtained as a purple powder. Yield $32 \mathrm{mg} \quad(70 \%)$. NMR ${ }^{1} \mathrm{H} \quad\left(\mathrm{CDCl}_{3}, \delta, \quad \mathrm{ppm}\right)$ : o.77-0.96 ( $m, 14 \mathrm{H}, 2$-ethylhexyl), 1.14-1.40 ( $m, 28 \mathrm{H}, 2$ ethylhexyl), 1.49-1.63 ( $m, 9 \mathrm{H}, 2$-ethylhexyl), 7.44-7.49 ( $d d d$, $\left.2 \mathrm{H},{ }^{3} J 7.6 \mathrm{~Hz}, 7.6 \mathrm{~Hz},{ }^{4} \mathrm{~J} 2.6 \mathrm{~Hz}, \mathrm{CH}_{\text {arom }}\right), 7.52-7.58(m, 1 \mathrm{H}$, $\left.\mathrm{CH}_{\text {arom }}\right), 7.64-7.67\left(m, 1 \mathrm{H}, \mathrm{CH}_{\text {arom }}\right), 7.67-7.70(m, 1 \mathrm{H}$, $\left.\mathrm{CH}_{\text {arom }}\right)$. IR $\left(\mathrm{v}, \mathrm{cm}^{-1}\right): 1660(\mathrm{C}=\mathrm{O})$.

\section{Results and discussion}

The synthesis of monomers 1 [17] and 2 [18] was carried out according to the described methods. Thus, compound 1 was obtained on the basis of commercially available precursor 3 as a result of successive $N$-alkylation and bromination of thiophene rings (Scheme 1 ). In the case of pyridylmonoazatriphenylene 2 , the starting compound is the previously described 3,11-dibromo-6-(pyridin-2-yl)-8,9dihydro-7 $H$-dibenzo $[f, h]$ cyclopenta $[c]$ quinoline 4 [20]. The monomer was obtained as a result of the Sonogashira reaction at two bromine atoms, followed by removal of the trimethylsilyl protection. The polymerization process was carried out in accordance with a modified technique under the conditions of the Sonogashira reaction [19]. The data of the ${ }^{1} \mathrm{H}$ NMR spectrum of the obtained polymer do not contradict its proposed structure. In the IR spectra, the presence of a vibration band corresponding to carbonyl groups in the region of $1660 \mathrm{~cm}^{-1}$ can be noted.

Next, we studied the photophysical characteristics of the obtained polymer 5 . In the solution of acetonitrile this polymer demonstrates absorption maxima around $550 \mathrm{~nm}$ (Table 1). Analysis of the literature data showed that, in the case of polymer $\mathbf{5}$, there is a bathochromic shift of the absorption maximum relative to the monomer units. Thus, for unsubstituted pyridylmonoazatriphenylene 6 [20], the longest wavelength absorption maximum corresponds to $357 \mathrm{~nm}$, and in the case of 2,5-bis(2-ethylhexyl)-3,6di(thiophen-2-yl)pyrrolo[3,4-c]pyrrole-1,4- $(2 H, 5 H)$-dione 7 [21] this parameter was $541 \mathrm{~nm}$. A similar bathochromic shift is observed for the emission maxima of polymer 5 relative to compounds 6 and 7. For example, there is a shift from $541 \mathrm{~nm}$ to $55 \mathrm{~nm}$. The absorption and emission spectra of the polymer are shown in Fig. 1.

Next, we studied the fluorescent response of the new polymer 5 with respect to cations of a number of metals. Thus, it was found that the addition of $\mathrm{Cu}^{2+}$ cation to the solution of polymer 5 in acetonitrile results in almost complete quenching of its fluorescence, which is due to the influence of both monomer units on the supramolecular properties of the whole polymer.

Fig. 2 depicts GPC chromatography for the resulting polymer 5. According to the obtained data, the resulting product $\mathbf{5}$ is a mixture of oligomers/short polymers, among which there are structures with molecular weights of up to 3-4 kDa. Thus, the method reported herein for the preparation of the polymer 5 requires further development in order to increase its average molecular weight.

Table 1 The photophysical characteristics for polymer 5 and compounds 6 and 7 in $\mathrm{MeCN}$ at room temperature
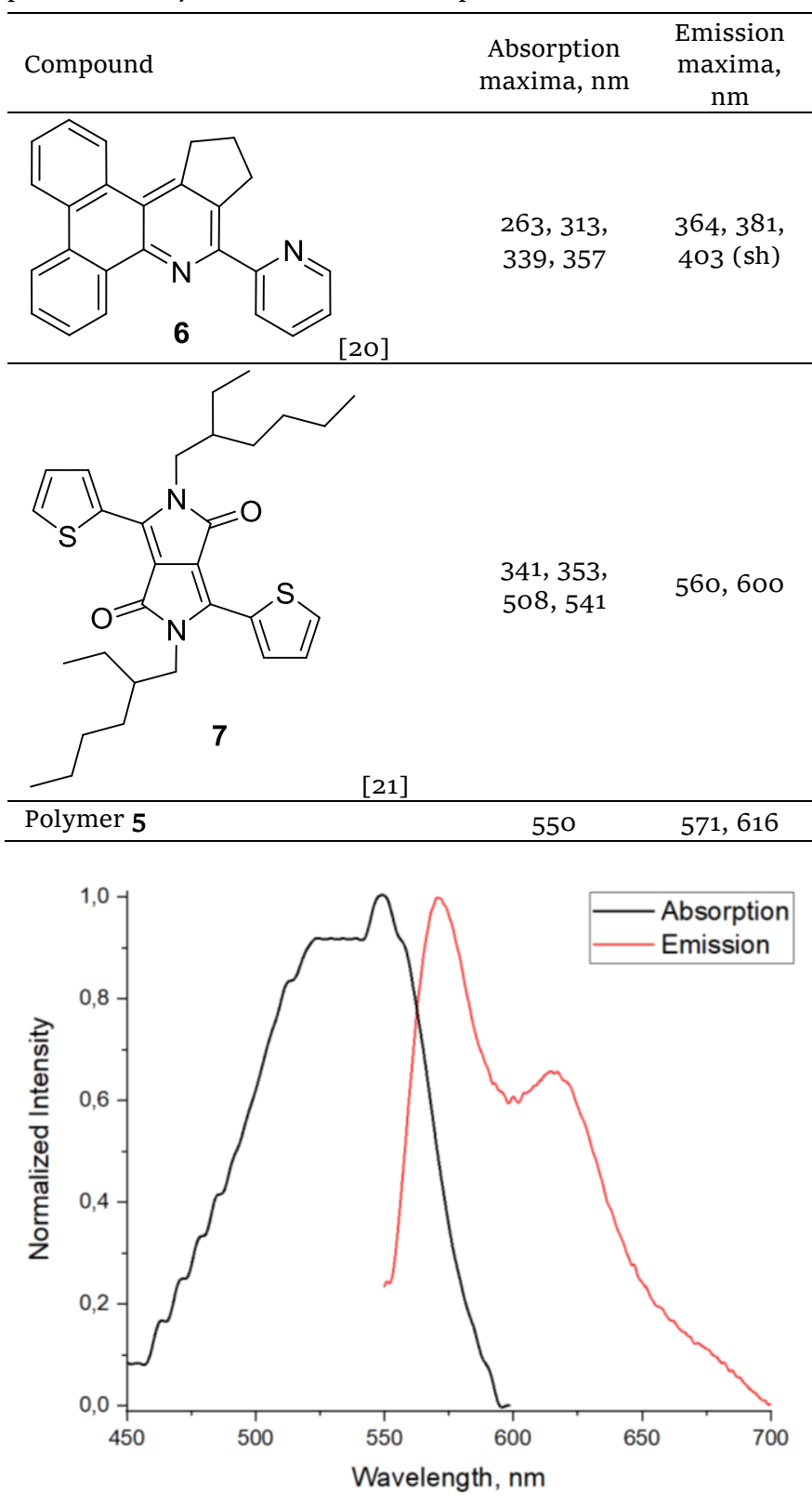

Fig. 1 Absorption and emission spectra of polymer 5 in acetonitrile at room temperature 


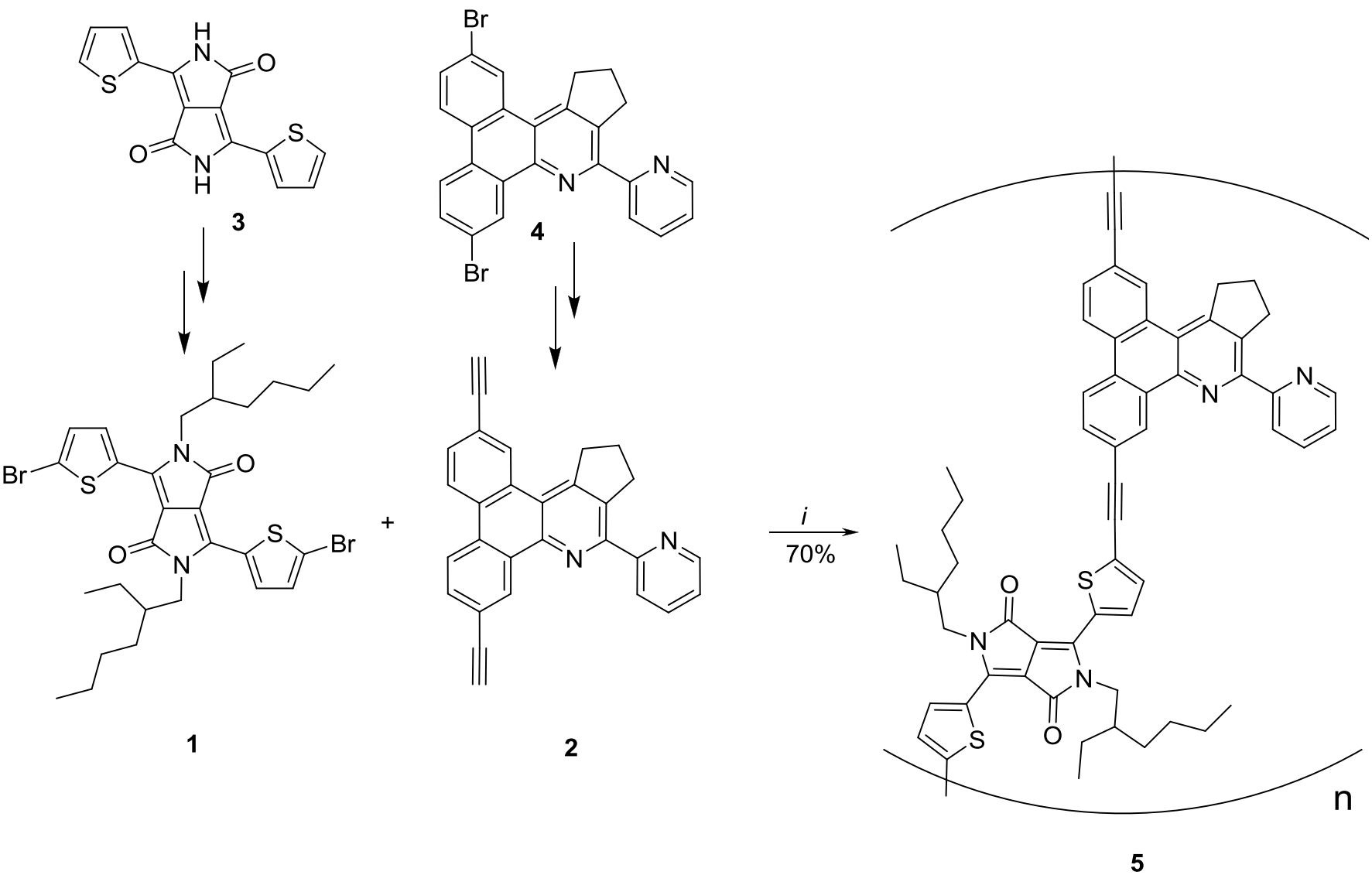

Scheme 1 Synthesis of polymer 5 . Reagents and conditions: i) CuI, $\mathrm{PPh}_{3}, \mathrm{Pd}(\mathrm{tpp})_{2} \mathrm{Cl}_{2} /$ diisopropylamine, $65{ }^{\circ} \mathrm{C}, 3$ days

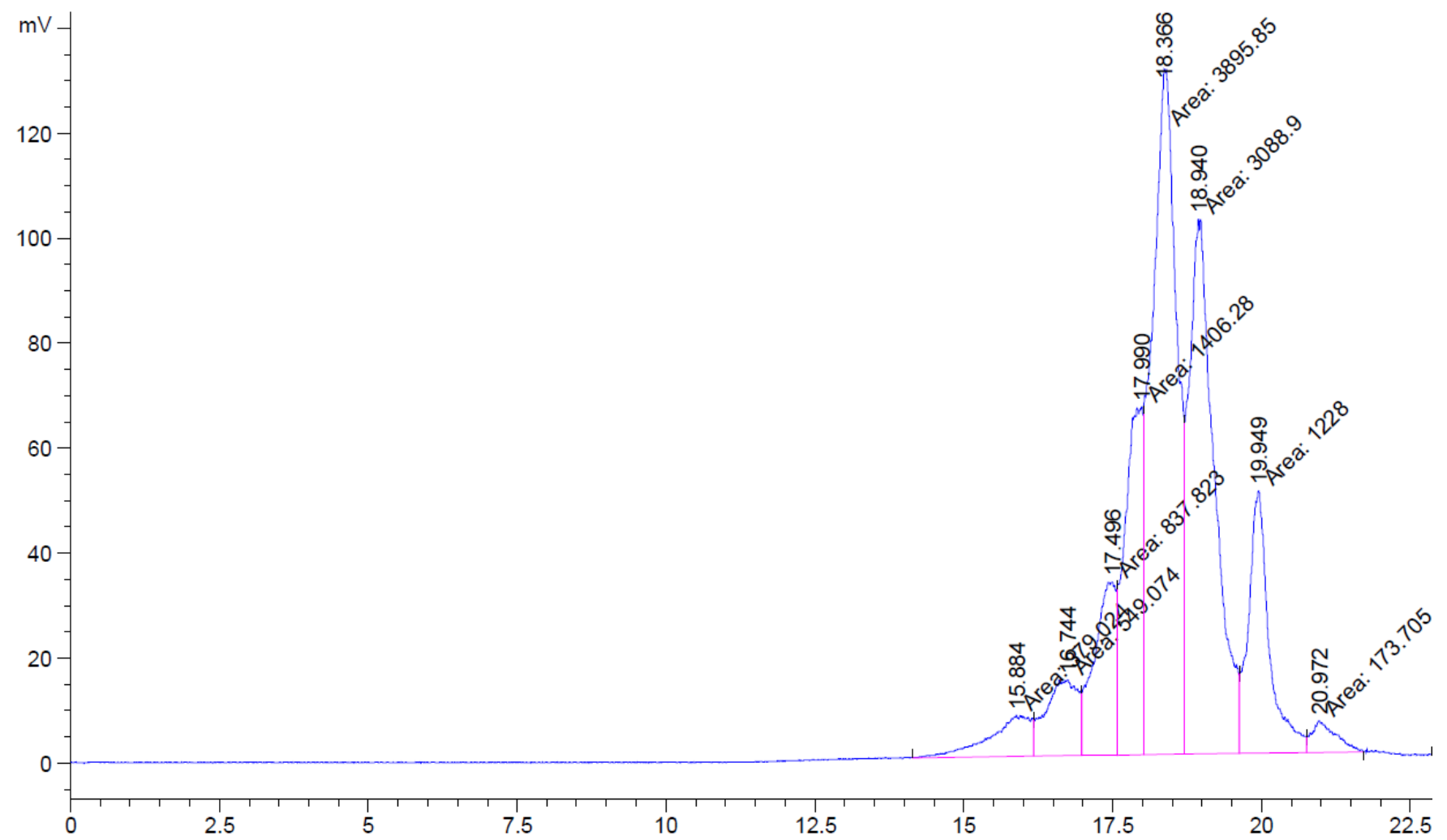

Fig. 2 GPC chromatogram for polymer 5 


\section{Conclusions}

In conclusion, a co-polymer containing 2-(2pyridyl)monoazatriphenylene and 2,5-bis(2-ethylhexyl)3,6-bis(thiophen-2-yl)pyrrolo[3,4-c]pyrrole-1,4(2 $H, 5 H)$ dione fragments as monomer units was prepared. Its photophysical properties were studied, and the bathochromic shift of the absorption and emission maxima in compare to those for monomer units was shown. Quenching of the fluorescence of the polymer in the presence of copper cations in solution was observed.

\section{Acknowledgements}

This work was supported by Russian Foundation for Basic Research (Grant № 19-53-55002). Zhuo Wang thanks National Natural Science Foundation of China (Grant № 81961138011) and Beijing Natural Science Foundation (Grant № 7192106).

\section{References}

1. Liu J, Lam JWY, Tang BZ. Acetylenic polymers: syntheses, structures, and functions. Chem Rev. 2009;109(11):57995867. doi:10.1021/cr9o0149d

2. Wang T, Zhang N, Baic W, Bao Y. Fluorescent chemosensors based on conjugated polymers with $\mathrm{N}$-heterocyclic moieties: two decades of progress. Polym Chem. 2020;11:3095-3114. doi:10.1039/dopyo0336k

3. Wang B, Wasielewski MR. Design and synthesis of metal ionrecognition-induced conjugated polymers: an approach to metal ion sensory materials. J Am Chem Soc. 1997;119(1):1221. doi:10.1021/jag62229d

4. Xing CF. Shi ZQ, Yu MH, Wang S. Cationic conjugated polyelectrolyte-based fluorometric detection of copper(II) ions in aqueous solution. Polymer. 2008;49(11):2698-2703. doi:10.1016/j.polymer.2008.04

5. Li C, Zhou C, Zheng H, Yin X, Zuo Z, Liu H, Li Y. Synthesis of a novel poly(para-phenylene ethynylene) for highly selective and sensitive sensing mercury (II) ions. J Polym Sci Part A: Polym Chem. 2008;46:1998-2007. doi:10.1002/pola.22534

6. Ha JS, Kim KH, Choi DH. 2,5-Bis(2-octyldodecyl)pyrrolo[3,4c]pyrrole-1,4- $(2 \mathrm{H}, 5 \mathrm{H})$-dione-based donor-acceptor alternating copolymer bearing 5,5'-di(thiophen-2-yl)-2,2'-biselenophene exhibiting $1.5 \mathrm{~cm}^{2} \cdot \mathrm{V}^{-1} \cdot \mathrm{s}^{-1}$ hole mobility in thin-film transistors J Am Chem Soc. 2011;133(27):10364-10367. doi:10.1021/ja203189h

7. Lee TW, Lee DH, Shin J, Cho MJ, Choi DH. $\pi$-Conjugated polymers derived from 2,5-bis(2-decyltetradecyl)-3,6di(selenophen-2-yl)pyrrolo[3,4-c]pyrrole-1,4(2H,5H)-dione for high-performance thin film transistors. Polym Chem. 2015;6(10):1777-1785. doi:10.1039/C4PY01536C

8. Lee JH, Park GE, Choi S, Lee DH, Um HA, Shin J, Cho MJ, Choi $\mathrm{DH}$. Effect of the thiophene and selenophene moiety in regular terpolymers on the performance of thin film transistors and polymer solar cells. Polymer. 2016;94:43-52. doi:10.1016/j.polymer.2016.04.037
9. Wei C, Zhang W, Zhou Y, Huang J, Li D, Wang Q, Yu G. Highperformance ternary $\pi$-conjugated copolymers containing diarylethylene units: synthesis, properties, and study of substituent effects on molecular aggregation and charge transport characteristics. J Mater Chem C. 2019;7:362-370. doi:10.1039/C8TCO4940H

10. Makoto F, Kunihiko K, Hiroshi Y, Keiichi M. Evaluation of new organic pigments as laser-active media for a solid-state dye laser. Dyes and Pigments. 2004;63(2):115-125. doi:10.1016/j.dyepig.2004.02.002

11. Ftouni H, Bolze F, Nicoud JN. Water-soluble diketopyrrolopyrrole derivatives for two-photon excited fluorescence microscopy. Dyes Pigm. 2013;97(1):77-83. doi:10.1016/j.dyepig.2012.11.028

12. Nie K, Dong B, Shi H, Chao L, Duan X, Jiang XF, Liu Z, Liang B. $\mathrm{N}$-alkylated diketopyrrolopyrrole-based ratiometric/fluorescent probes for $\mathrm{Cu}^{2+}$ detection via radical process. Dyes Pigments. 2019;160:814-822. doi:10.1016/j.dyepig.2018.09.027

13. Nie K, Dong B, Shi H, Liu Z, Liang B. Thienyl diketopyrrolopyrrole as a robust sensing platform for multiple ions and its application in molecular logic system. Sensor Actuator B Chem. 2017;244:849-853. doi:10.1016/j.snb.2017.01.037

14. Grzybowski M, Gryko DT. Diketopyrrolopyrroles: synthesis, reactivity, and optical properties. Adv Optical Mater. 2015;3(3):280-320. doi:10.1002/adom.201400559

15. Jianga X, Wanga L, Tanga H, Caoa D, Chen W. Diketopyrrolopyrrole: an emerging phototherapy agent in fighting cancer. Dyes Pigments. 2020;181:108599-609. doi:10.1016/j.dyepig.2020.108599

16. Jin X, Xing X, Deng Q, Qing W, Liu Z, Huang Y. Molecular engineering of diketopyrrolopyrrole-conjugated polymer nanoparticles by chalcogenide variation for photoacoustic imaging guided photothermal therapy. J Mater Chem B. 2021;9:3153316o. doi:10.1039/D1TBoo193K

17. Wang P, Li H, Gu C, Dong H, Xua Z, Fu H. Air-stable ambipolar organic field-effect transistors based on naphthalenediimidediketopyrrolopyrrole copolymers. RSC Adv. 2015;5:1952019527. doi:10.1039/C5RAo0391A

18. Khasanov AF, Kopchuk DS, Krinochkin AP, Kovalev IS, Taniya OS, Suvorova AI, Zyryanov GV, Rusinov VL, Chupakhin ON. 2,7-diehtynyl-10-(pyridin-2-yl)-12,13-dihydro-11Hdibenzo[f,h]cyclopenta[c]quinoline as potential monomer for creating polymers for different tasks. AIP Conf Proc. 2020;2280:040021-040024. doi:10.1063/5.0018783

19. Yang JS, Swager TM. Fluorescent Porous Polymer Films as TNT Chemosensors: Electronic and Structural Effects. J Am Chem Soc. 1998;120:11864-11873. doi:10.1021/ja9822939

2o. Kopchuk DS, Khasanov AF, Kovalev IS, Zyryanov GV, Kim GA, Nikonov IL, Rusinov VL, Chupakhin ON. The extension of conjugated system in pyridyl-substituted monoazatriphenylenes for the tuning of photophysical properties. Chem Heterocycl Comp. 2014;50(6):871-879. doi:10.1007/s10593-014-1541-0

21. Chakali M, Mandal H, Venkatesan M, Dyaga B, Rao VJ, Bangal PR. Charge separation and singlet fission in covalently linked diketopyrrolopyrrole derivatives and triphenylamine triad in solution. J Photochem Photobiol A: Chem. 2021;406:113017113028. doi:10.1016/j.jphotochem.2020.113017 